\title{
Development of Supersonic Combustion Experiments for CFD Modeling
}

\author{
Andrew D. Cutler ${ }^{*}$ and Gaetano Magnotti ${ }^{\dagger}$ \\ The George Washington University, Newport News, VA, 23602 \\ Robert Baurle ${ }^{\ddagger}$, Daniel Bivolaru ${ }^{\S}$, Sarah Tedder ${ }^{* *}$, and Paul M. Danehy ${ }^{\dagger \dagger}$ \\ NASA Langley Research Center, Hampton, VA, 23681
}

\begin{abstract}
This paper describes the development of an experiment to acquire data for developing and validating computational fluid dynamics (CFD) models for turbulence in supersonic combusting flows. The intent is that the flow field would be simple yet relevant to flows within hypersonic air-breathing engine combustors undergoing testing in vitiated-air ground-testing facilities. Specifically, it describes development of laboratory-scale hardware to produce a supersonic combusting coaxial jet, discusses design calculations, operability and types of flames observed. These flames are studied using the dual-pump coherent antiStokes Raman spectroscopy (CARS) - interferometric Rayleigh scattering (IRS) technique. This technique simultaneously and instantaneously measures temperature, composition, and velocity in the flow, from which many of the important turbulence statistics can be found. Some preliminary CARS data are presented.
\end{abstract}

\section{Nomenclature}

Variables:

$E R=$ Equivalence ratio

$H=$ Convective heat transfer coefficient

$M=$ Mach number at nozzle exit

$M_{c}=$ Convective Mach number

$M_{\text {enthalpy }}=$ Flight Mach number with the same enthalpy

$q_{w}=$ Surface heat flux

$r=$ Radial distance

$T=$ Nozzle exit static temperature

$T_{\text {wall }}=$ Burner interior wall temperature

$x=$ Axial distance
Flame state labels:

$\mathrm{NF}=$ No flame

$\mathrm{DF}=$ Detached flame

$\mathrm{EAF}=$ External attached flame

$\mathrm{BAF}=$ Base attached flame

$\mathrm{M}=$ Flame marginal stability

$0=$ Burner would not light

\section{Introduction}

Constan omputational fluid dynamics (CFD) methods that employ the Reynolds-averaged Navier-Stokes (RANS) equations are widely used in the design and analysis of hypersonic airbreathing engine flow paths. These methods require models of statistical quantities of the turbulence, which have to be empirically calibrated and validated. In particular, new models for turbulent Schmidt and Prandtl number, as well as for turbulence-chemistry interactions, are required. ${ }^{1}$ While suitable data is available for low-speed flows with combustion, data is still lacking in supersonic combustion. Goyne et $\mathrm{al}^{2}{ }^{2}$ report measurements using particle-imaging velocimetry of mean streamwise velocity in a dual-mode scramjet. At NASA Langley, several data sets have been acquired in a $\mathrm{H}_{2}$ fueled supersonic combustor using the coherent anti-Stokes Raman spectroscopy (CARS) technique ${ }^{3}$ and the dual-

\footnotetext{
* Professor, MAE Dep’t, 1 Old Oyster Point Road, Suite 200. Associate Fellow AIAA

${ }^{\dagger}$ Graduate student, Student Member AIAA

* Senior Research Scientist, Hypersonic Air Breathing Propulsion Branch. Member AIAA

$\S$ Postdoctoral Fellow at NASA Langley Research Center. Member AIAA

${ }^{* *}$ NASA coop and graduate student, College of William and Mary, Williamsburg, VA 23669. Member AIAA

† Senior Research Scientist, Advanced Sensing and Optical Measurements Branch. Associate Fellow AIAA
} 
pump CARS technique originally developed by Robert Lucht and coworkers ${ }^{4,5}$ and extended by us. ${ }^{6,7}$ The former technique gave temperature only while the latter gave both temperature and composition. Data included both mean flow and turbulent statistics, although the uncertainty in the latter was high due to both instrument precision and the number of measurements from which the statistics were formed. International work in this area includes measurements in scramjet combustors conducted at ONERA (France) and DLR (Germany) using CARS ${ }^{8}$, and other non-intrusive techniques.

Available data sets are limited to only a subset of the important variables (which are temperature, composition, and velocity) and data sets that include accurate turbulence statistics do not exist. To meet the need for instantaneous velocity measurements to complement dual-pump CARS measurements of temperature and composition, the interferometric Rayleigh scattering technique is being developed. ${ }^{9,10}$ This technique uses Rayleigh scattering from one of the CARS laser beams to measure velocity in the same instant as the CARS measurement. Analysis of streams of such instantaneous measurements allows us to form the statistical quantities (means, variances, covariances) required by the modelers.

Experimental facilities to provide suitable flow fields are also being developed. ${ }^{11,12}$ An axisymmetric coaxial free jet has been selected since it can provide the good optical access required for the Rayleigh technique, and symmetry can be taken advantage of to minimize the number of spatial points required. (In order to form accurate statistics we need large numbers of measurements at each given point.) The flow field needs to provide data that is relevant to both $\mathrm{H}_{2}$ - and hydrocarbon-fueled hypersonic air-breathing engines and the testing of such engines in ground facilities that employ vitiated air (the products of combustion of either $\mathrm{H}_{2}$ or a hydrocarbon, enriched with $\mathrm{O}_{2}$ to the same content as in air). The facility needs to provide supersonic flows to establish the effects of compressibility. Finally, it is desirable to be able to create both supersonic combusting flows in which the flame is attached to the burner (flame held) and flows in which the flame is detached, since both types of flow are observed in hypersonic engine combustors.

Two different sizes of experimental hardware are being developed. The first is a laboratory-scale supersonic burner, with flow rates compatible with testing in a combustion diagnostics laboratory. The center jet nozzle exit diameter of this device is $10 \mathrm{~mm}$. This device is being used to develop the test matrix of experiments and to verify the CARS-IRS techniques. However the CARS measurement volume is $\sim 1.5$ $\mathrm{mm}$ long, of the same order of magnitude of some of the length scales of the flow. Thus, the capstone experiments of this project will be performed in NASA Langley's Direct Connect Supersonic Combustion Test Facility (DCSCTF) with hardware that is scaled up by a factor of 6.35 from the smaller device in its important flow dimensions (although the mechanical design is different). The present paper describes the development of the experimental hardware for the laboratory device, the test matrix used and the verification of the CARS-IRS instrumentation.

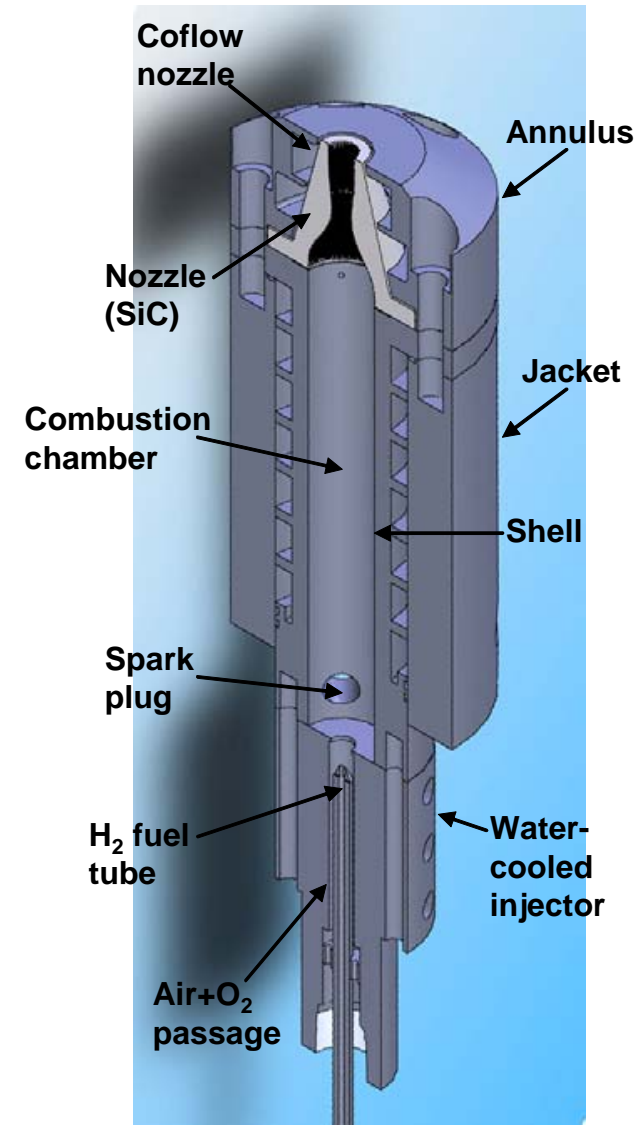

Figure 1. Sectional view of laboratory supersonic burner.

\section{Supersonic Burner}

\section{A. Description}

Figure 1 shows the laboratory-scale burner, sectioned along the axis, shown without bolts, gas supply lines, spark plug and other fittings; Figure 2 is an image obtained obtained near the nozzle exit during operation, showing a Mach 2 jet of vitiated air and the laser beams of the CARS-Rayleigh system. The burner consists of a combustion chamber, $25.4 \mathrm{~mm}$ internal diameter and $152 \mathrm{~mm}$ in length, formed by an exterior "jacket" and an interior "shell" between which cooling water flows. An axisymmetric piece contains a central nozzle with an exit diameter of 10 
$\mathrm{mm}$. This "nozzle" is interchangeable and convergent $(M \leq 1)$, or supersonic convergent-divergent $(M=1.6$ and $M=2$ ) nozzles are available. Nozzles are designed using the axisymmetric method of characteristics with fixed ratio of specific heat capacities. ${ }^{13}$ The nozzle is trapped by an "annulus" and an annular coflow nozzle passage is formed between it and the annulus. The coflow nozzle passage is convergent with exit width (in the radial direction) of 1 $\mathrm{mm}$. The annular base region of the nozzle, between the central jet and coflow, is normal to the axis and 3-mm wide. Reactants at ambient temperature are delivered to the burner by the "injector", which contains a central tube through which gaseous fuel flows, while a mixture of $\mathrm{O}_{2}$ (or sometimes $\mathrm{N}_{2}$ ) and air flows in a concentric passage. This coflow of reactants enters the burner through a sudden expansion. The injector, jacket, shell, and annulus are fabricated from AISI 310 stainless steel and the nozzle is fabricated from Hexaloy grade SA silicon carbide. ${ }^{14}$

Various combinations of reactants are possible. In one set of experiments $\mathrm{H}_{2}$ or $\mathrm{C}_{2} \mathrm{H}_{4}$ fuel, air, and $\mathrm{O}_{2}$ are reacted to provide vitiated air at various temperatures (dependent on flow rates). The coflow is of unheated $\mathrm{H}_{2}$ or $\mathrm{C}_{2} \mathrm{H}_{4}$. In another set of experiments the reactants to the burner are $\mathrm{H}_{2}, \mathrm{O}_{2}$ (sometimes $\mathrm{N}_{2}$ is used instead of $\mathrm{O}_{2}$ ), and air in such a ratio that the products contain excess $\mathrm{H}_{2}$ (rather than excess $\mathrm{O}_{2}$ ). The coflow in this case is air. In both cases, the resulting coaxial jet flow will mix and may react depending on nozzle exit Mach number and temperature. If reaction does take place, then the flame may be held at the burner or stand off from it, depending again on temperature and Mach number. Cases for the study of mixing without reaction in the jet are also possible by employing vitiated air, or products containing reduced excess $\mathrm{O}_{2}$, both with air coflow.

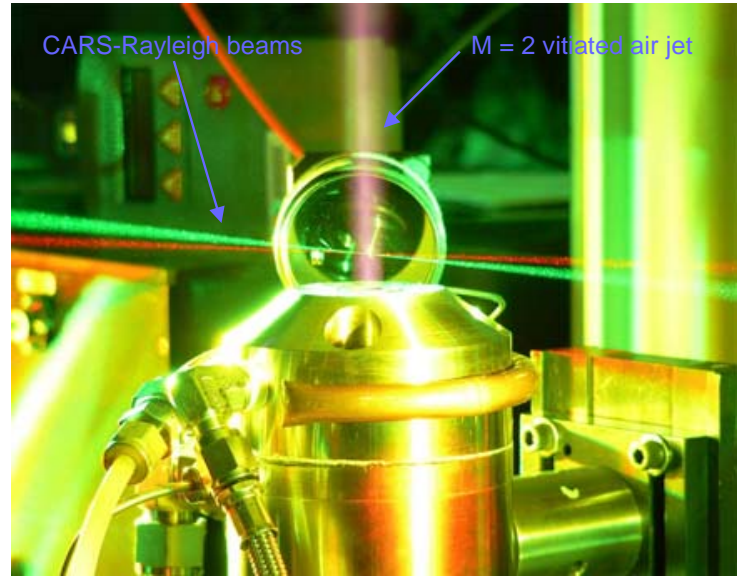

Figure 2. Image of the supersonic burner during CARS-Rayleigh optical system data acquisition.

\section{B. Test Matrix Calculations}

Burner stagnation and nozzle exit conditions are calculated from flow rates, heater pressure, and nozzle minimum and exit areas using an inviscid quasi-one-dimensional (1D) analysis ${ }^{15}$. The flow in the burner is assumed to be fully mixed (uniform in composition and thermodynamic state) and in thermodynamic equilibrium before entering the nozzle. The heat loss to the burner structure and cooling water is assumed, based on experience in the DCSCTF, to be $20 \%$ of the sensible enthalpy increase (i.e., the heat that would be released in bringing the products at constant pressure back to the temperature of the entering reactants). Thus, the product's enthalpy is reduced by this amount. The nozzle flow is computed by 1D analysis, assuming isentropic, choked flow of frozen composition in the nozzle. Nozzle exit conditions are computed from the geometrical nozzle throat and exit area and neglect any displacement effect of boundary layers. Nozzle exit pressure is forced to be one atmosphere and reactant temperature is assumed to be $298 \mathrm{~K}$. All significant minor species are included. Other calculations assuming equilibrium rather than frozen chemistry in the nozzle result in significant differences in minor species composition, but insignificant differences $(<1 \%)$ in major species, temperature, pressure, and velocity. The nozzle exit thermodynamic conditions for vitiated air products are related to an equivalent flight Mach number. The equivalent flight Mach number has the same total sensible enthalpy (sensible enthalpy based on static conditions relative to a standard state plus kinetic energy), where flight is assumed to be in the atmosphere on a constant dynamic pressure trajectory of 1000 pounds force per square foot.

"Convective" Mach number $\left(M_{c}\right)$ has been computed at the nozzle exit by the method of Papamoschou and Roshko. ${ }^{16}$ These authors were able to correlate the growth rate of planar two-stream mixing layers, when normalized by the growth rate of incompressible layers of the same velocity and density ratio, in terms of $M_{c}$. Two convective Mach numbers were defined, being the magnitude of the difference between the convective velocity of the mixing layer coherent structures and one of the streams, divided by the speed of sound of the respective free stream. A simple analytical method gave convective Mach numbers for each stream that were nearly equal. When correlated with $M_{c}$, growth rates normalized by the growth rate of the incompressible layers were found to fall from 1.0 for $M_{c}$ $<0.2$ to $\sim 0.2$ for $M_{c}>0.7$. In our computations of $M_{c}$, the center jet is assumed to be the high speed stream and the (stationary) ambient air the low. Our axisymmetric, annular flow does not closely resemble the simple planar twostream mixing layer; $M_{c}$ here is used simply as a guide to the importance of compressibility. 

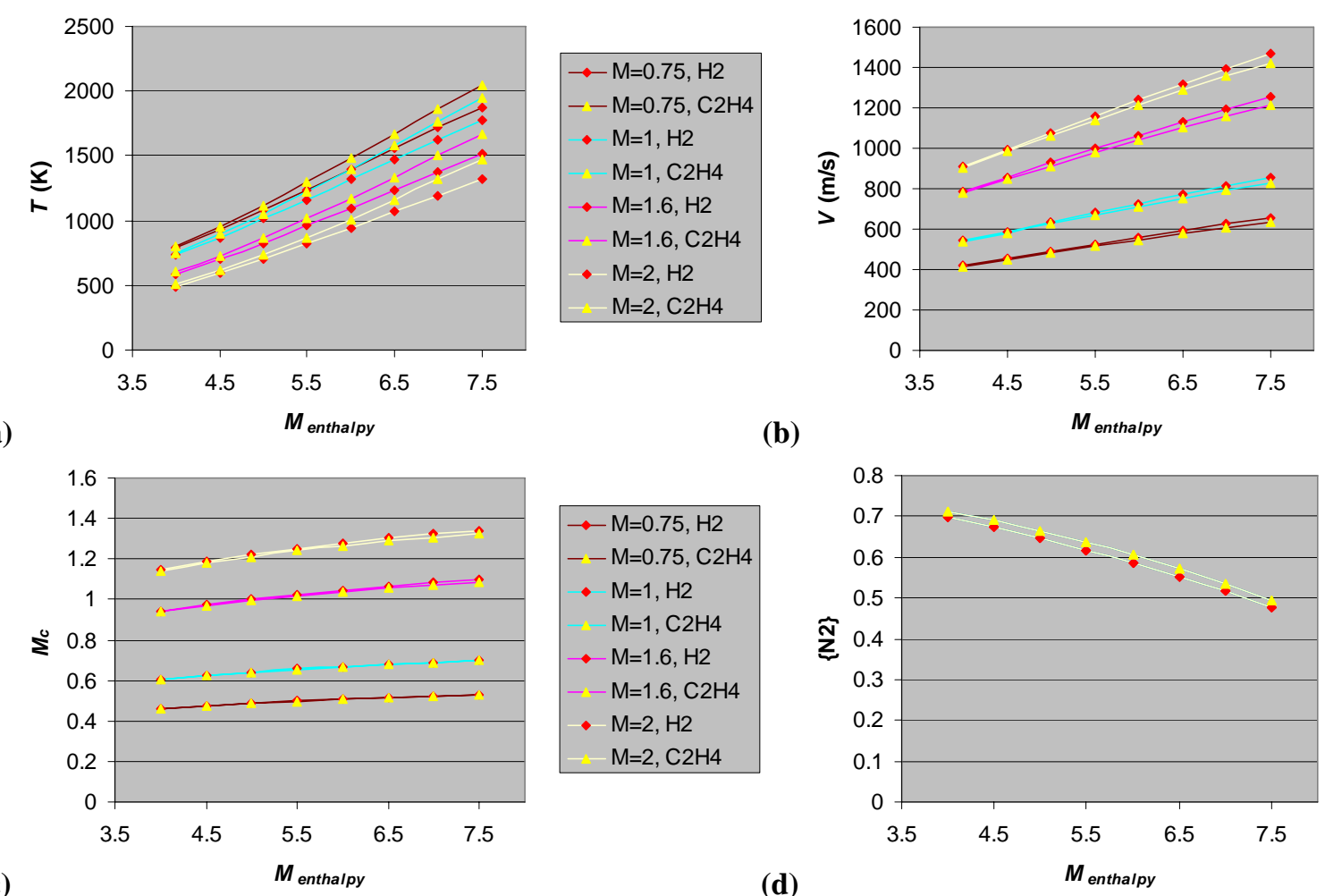

(c)
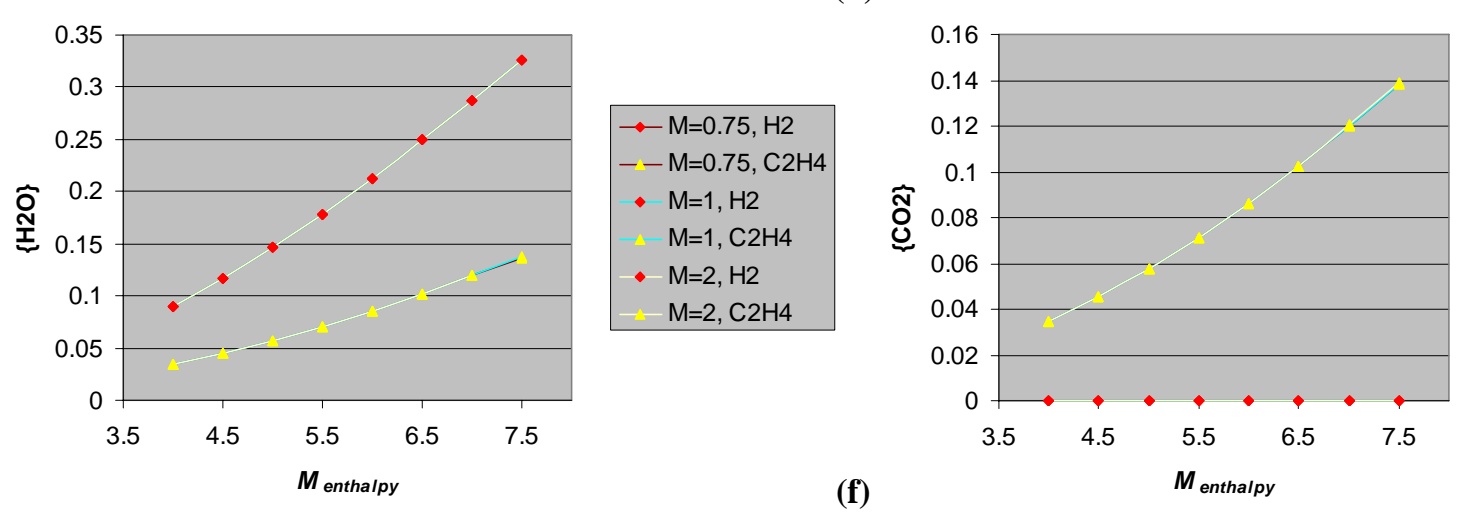

(e)

Figure 3 Computed conditions at exit of center jet nozzle for various cases of vitiated air, with $M$ of $0.75,1$, 1.6 and 2, and with vitiate produced by combustion of $\mathrm{H}_{2}$ and $\mathrm{C}_{2} \mathrm{H}_{4}$; plotted as a function of equivalent flight Mach number. (a) Static temperature, (b) velocity, (c) $M_{c}$; mole fractions respectively of (d) $\mathrm{N}_{2}$, (e) $\mathrm{H}_{2} \mathrm{O}$ and (f) $\mathrm{CO}_{2}$.

A matrix of calculations has been performed for cases in which the center jet is vitiated air (that is contains $23 \%$ by mass $\mathrm{O}_{2}$ ). The burner fuel is either $\mathrm{H}_{2}, \mathrm{CH}_{4}$ (methane), or $\mathrm{C}_{2} \mathrm{H}_{4}$ (ethylene). Methane was later dismissed as a practical fuel since it was found not to react in our burner, at least over the range of reactant compositions we were interested in studying. Ethylene has the disadvantage that, although gaseous and more reactive than methane, has a relatively low vapor pressure and under certain circumstances can form droplets in the supply lines. Figure 3 shows the results for nozzle-exit conditions. Figure 3(a) shows the nozzle-exit temperature (T), which is seen to increase rapidly with increasing equivalent flight Mach number, and decrease with nozzle Mach number. There is also some effect of burner fuel, with temperatures increasing with carbon content. Figure 3(b) shows the nozzle-exit velocity, which is seen to increase rapidly with both equivalent flight Mach number and nozzle Mach number. There is little effect of burner fuel on velocity. Figure 3(c) shows that $M_{c}$ depends principally on nozzle Mach number, being in the fully compressible range at $M=1.6$ and 2, and at the upper end of the transitional range for $M=1$. Molecular nitrogen mole fraction (Fig. 3d) is dependent primarily on equivalent flight Mach number, while $\mathrm{H}_{2} \mathrm{O}$ (Fig. 3e) and $\mathrm{CO}_{2}$ (Fig. 3f) mole fractions depend on equivalent flight Mach number and carbon content of the fuel. 
A similar matrix of calculations has been performed for cases in which the center jet contains excess $\mathrm{H}_{2}$ (rather than $\mathrm{O}_{2}$ ) in mole fractions of $33 \%, 50 \%$ and $67 \%$, the so called "vitiated hydrogen" cases. The burner fuel is, of course, $\mathrm{H}_{2}$. Figure 4 shows the results for nozzle exit conditions. Nozzle exit velocity (Fig. 4a) increases with $T, M$, and $\mathrm{H}_{2}$ content, and is generally higher than with vitiated air. Convective Mach number is again primarily dependent upon $M$ (Fig. 4b), being in the fully compressible range for the $M=1.6$ and 2 . Water vapor content increases with $T$ and $M$ (Fig. 4c).
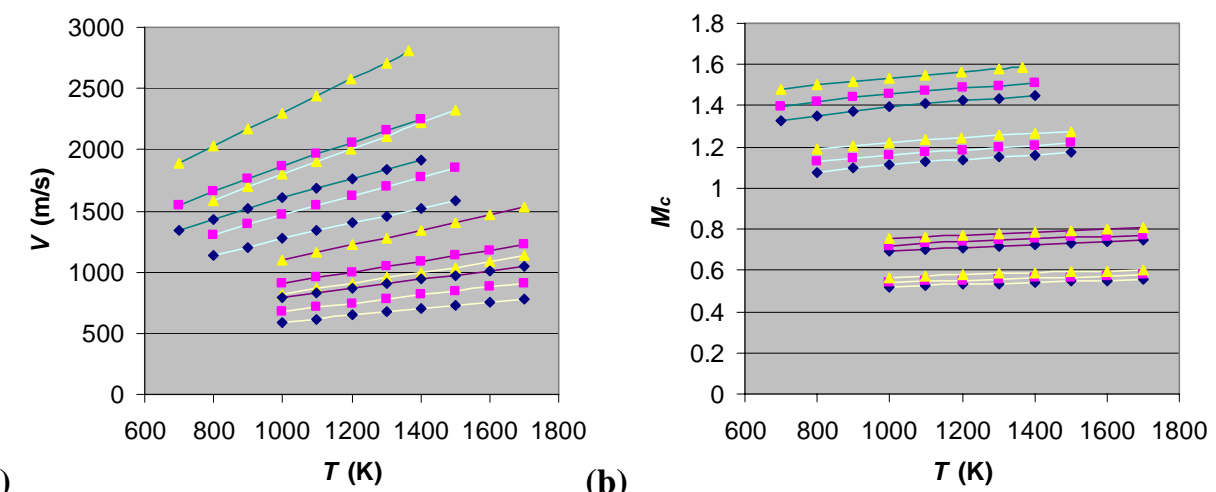

(a)
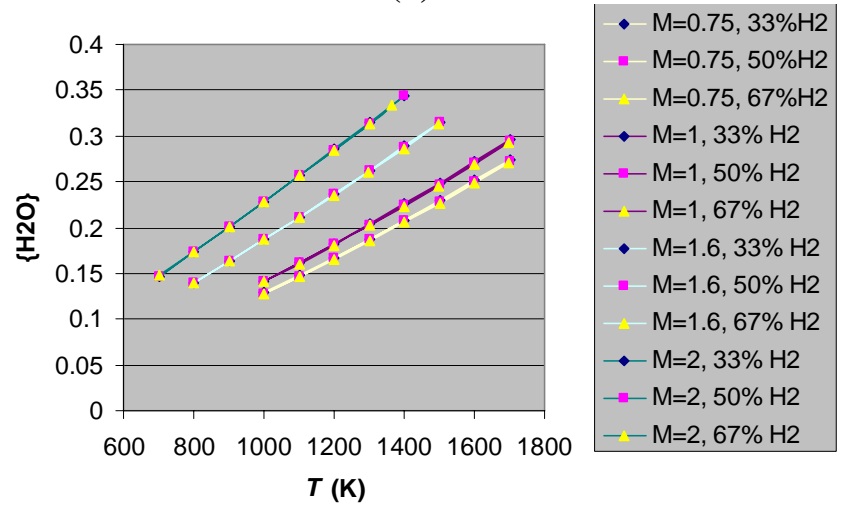

(c)

$T(\mathrm{~K})$

Figure 4 Computed conditions at exit of center jet nozzle for various cases of vitiated hydrogen, with $M$ of $0.75,1,1.6$ and 2; plotted as a function of static temperature at nozzle exit. (a) Velocity, (b) $M_{c}$, (c) mole fraction of $\mathrm{H}_{2} \mathrm{O}$.

As has been seen, a wide range of variation of parameters of the center jet is possible. Additionally, the coflow composition and rate of flow may be varied. An overall equivalence ratio, $E R$, is defined for cases with vitiated air as the rate of coflow fuel to exactly consume the excess $\mathrm{O}_{2}$ in the center jet. Typically, ER is 0.5 or 1.0.

Experimentally, it was found (based on IR imaging) that cases with $\mathrm{CH}_{4}$ coflow would not react significantly for our test conditions, although visible light emission suggested that some dissociation of the fuel was taking place. If the coflow was air, the rate of flow of air was computed so as to provide sonic flow at the coflow nozzle exit with pressure matched to the atmosphere. This latter condition was believed, based on CFD analysis, ${ }^{11}$ to be conducive to flame holding at the base for those experiments in which the center jet was vitiated hydrogen.

\section{Detailed Design Calculations}

Detailed design calculations of the burner were performed for a high heat transfer rate case: $T=1200 \mathrm{~K}, M=2$, and $50 \%$ unreacted $\mathrm{H}_{2}$. The objectives of these calculations were to determine whether combustion would stabilize within the burner, whether the flow at the exit of the burner was uniform, and whether the burner component temperatures and stresses exceeded material limits. Two types of calculation were performed: calculations of the internal flow of the burner using computational fluid dynamics, and calculations of the temperature and stresses in the burner structure using finite elements analysis. These calculations were coupled via a computed surface heat transfer coefficient distribution.

The Vulcan CFD code ${ }^{17}$ was used to solve the Favre-averaged Navier-Stokes equations on a structured grid using the finite-volume method. The flow is assumed to be axisymmetric, and mixtures of thermally perfect gases were assumed. Inviscid fluxes were calculated using the Kappa $=1 / 3^{\text {rd }}$ MUSCL scheme with the Low Diffusion 
Flux Split Scheme of Edwards ${ }^{18}$, while viscous fluxes were evaluated using $2^{\text {nd }}$ order central differences. A diagonalized approximate factorization scheme was used for iterating the unsteady equations in pseudo-time to a steady-state solution. The grid, consisting of 31,248 grid points, was generated by a separate, commercial code. The gridded volume terminated at the nozzle exit. Grid points were clustered near the walls of the nozzles to resolve the boundary layers, as appropriate for the use of wall functions, and in the throat and expanding region of the nozzle. Turbulence was modeled using the Wilcox k- $\omega$ model (1998). ${ }^{19}$ Calculations were performed at two isothermal surface conditions: the first with a constant $900 \mathrm{~K}$ throughout, the second with $900 \mathrm{~K}$ for the steel components switching to $1650 \mathrm{~K}$ for the silicon carbide nozzle. Reactants were assumed to enter the burner in a premixed state as sonic flow through a 0.1 inch diameter hole on the axis. Entering reactant (static) properties were $1.463 \times 10^{6} \mathrm{~Pa}, 248 \mathrm{~K}$, and mass fractions of $\mathrm{H}_{2}, \mathrm{O}_{2}$, and air respectively of $0.130,0.227$, and 0.643 , computed as described in Section IIIB. Total pressure and temperature conditions were specified at subsonic inflow/outflow planes, while the code switched to extrapolation where the outflow is supersonic.
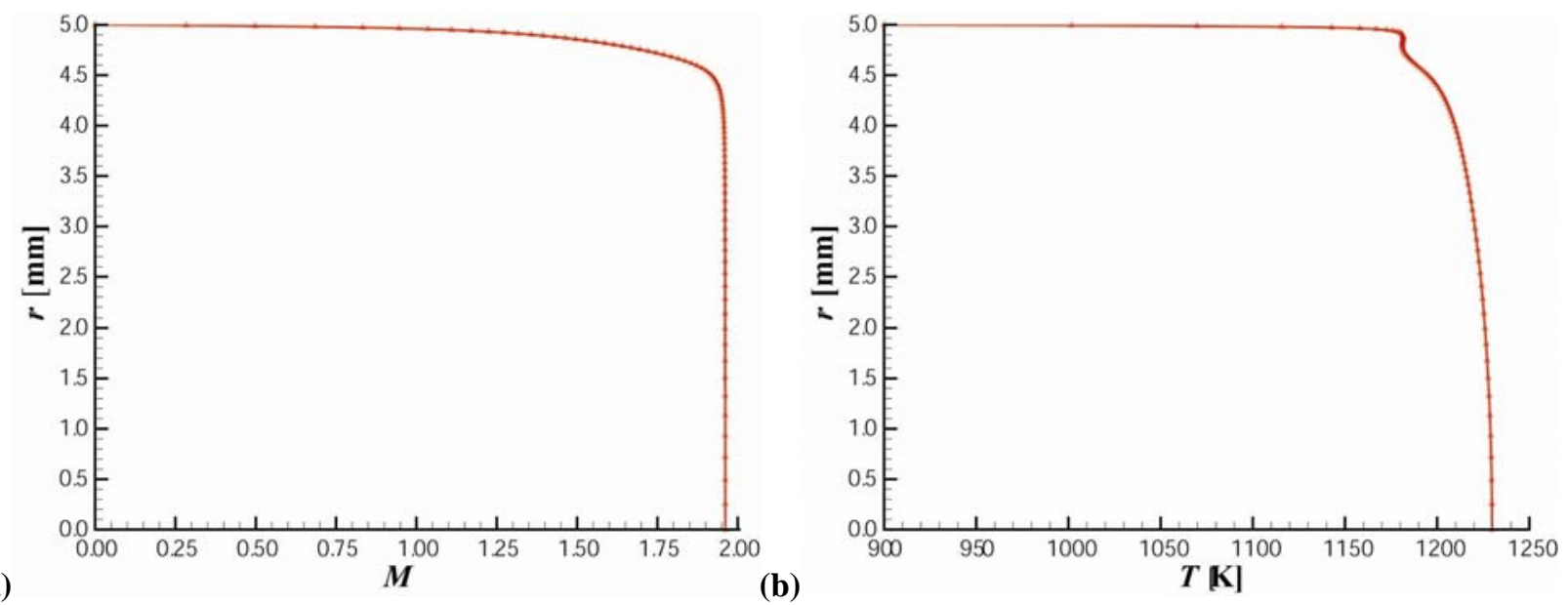

Figure 5 CFD calculated properties at the nozzle exit for the nominal $T=1200 \mathrm{~K}, M=2$ case with $T_{\text {wall }}=900 \mathrm{~K}$; properties are plotted on the horizontal axis as a function of radial distance on the vertical. (a) $M$, (b) $T$.

As the burner is currently (experimentally) configured, the reactants are not premixed when they enter the burner (see Fig. 1 and Section IIIA), as assumed in the computations. The computed configuration was in fact attempted experimentally. However, flashback into the supply lines occurred during the startup transient due to the pressure in the burner greatly exceeding the steady state immediately after igniting the reactants in the burner. It was possible to work around this problem by, for example, lighting at low fuel-air equivalence ratio and then increasing flows to the final condition. And a premixed flow entering the burner was desirable because it simplified computations and guaranteed uniform composition of the products. However, the desire for robust and safe operation outweighed these other considerations.

Some of the results of our calculations are shown in Figs. 5 and 6. Figure 5 shows properties at the nozzle exit. The Mach number (Fig. 5a) is close to the design value of 2.0 in the freestream, and falls to zero at the wall, as expected. The static temperature (Fig. 5b) is a little higher than $1200 \mathrm{~K}$ at the axis and drops to $900 \mathrm{~K}$ at the wall. The $1200 \mathrm{~K}$ design value represents the mass flow weighted mean (accounting for heat losses to the walls of the burner), so the high value at the axis for this computation is to be expected. The calculated nozzle exit pressure varies between $107.12 \mathrm{kPa}$ and $107.34 \mathrm{kPa}$, a small range but higher than the design $101.3 \mathrm{kPa}$. This discrepancy is attributed to the effect of the boundary layer displacement, which reduces the effective flow area at the nozzle throat.

Figure 6 shows the surface heat transfer coefficient, plotted as a function of axial distance from the nozzle exit, computed based on the surface heat flux, $q_{w}$, and an assumed recovery temperature of $2000 \mathrm{~K}$ :

$$
H=q_{w} /\left(2000-T_{w}\right)
$$

The results show a tolerable collapse of the two different wall temperatures cases. As our later calculations will show, the actual nozzle wall temperature lies between $900 \mathrm{~K}$ and $1650 \mathrm{~K}$, and $900 \mathrm{~K}$ is a reasonable average value for the burner. Thus, the computed $H(x)$ for the $T_{\text {wall }}=900 \mathrm{~K}$ case forms a reasonable conservative estimate for the calculations that follow. 
The temperature and thermal stress distributions in the burner assembly were computed using a commercial CAD solid modeling and finite-elements package that also included a flow solver. A number of calculations were performed as the hardware design was iterated. One significant issue was the manner in which the silicon carbide nozzle was held. If the contact surface between the steel components of the burner and the nozzle was rigid ("bonded") and conducting, stresses were very high in the nozzle (greatly exceeding the limits of the material). This had two causes. First, severe temperature gradients in the shell caused the contact surface with the nozzle to tend to distort. Second, conduction from the nozzle induced temperature gradients within the nozzle itself, inducing thermal stresses. These problems, once identified, were easily mitigated by using soft, graphite gaskets which, in addition to providing a seal, absorb the distortion and somewhat increase thermal contact resistance. Calculations presented assume that the nozzle was unconstrained from expansion, and that the annulus and shell imposed no stresses on the nozzle, having assumed that the graphite gasket is able to absorb them.

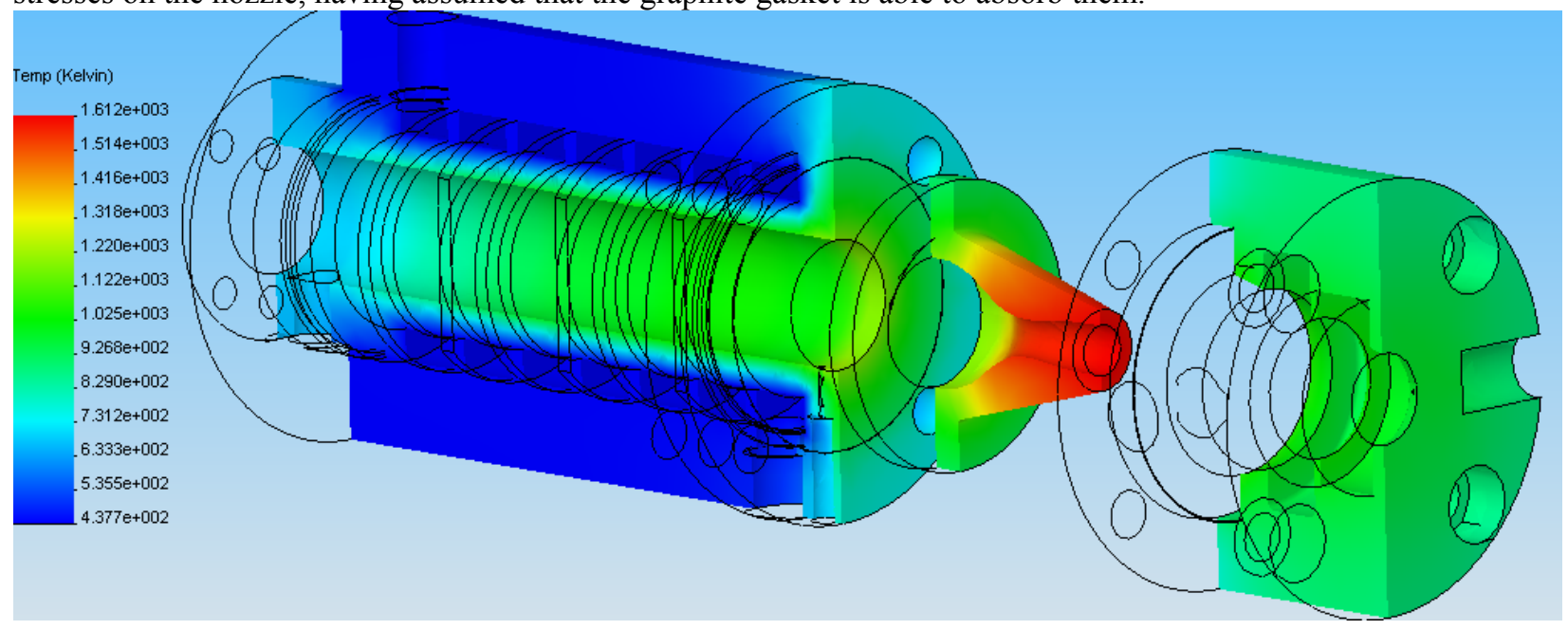

\section{Figure 7 Finite elements solution for temperature distribution in burner assembly}

One representative calculation is presented here (Fig. 7) in which the shell, nozzle and annulus are in the steadystate condition. The flow surface heat transfer is modeled using Equation (1). The surfaces of the water-cooling passages are set to $373 \mathrm{~K}$, while the annulus radiates to the surroundings, assumed black at $300 \mathrm{~K}$. Heat transfer between the nozzle and the annulus is by both conduction and radiation. Emissivity of the nozzle is assumed 0.9 and of the annulus 0.7. Components conduct where they contact, except that a thermal resistance $0.0001 \mathrm{~m}^{2} \mathrm{~K} / \mathrm{W}$ is placed between the nozzle and the annulus and between the nozzle and the shell to model a graphite gasket of 0.5 $\mathrm{mm}$ thickness. No flow is assumed in the coflow passage. This latter point is important since, in all our experiments described below, there is a coflow, which cools the nozzle and annulus.

The maximum temperature in the steel is $1180 \mathrm{~K}$, below the maximum service temperature in air (which is 1310 $\mathrm{K}$ for intermittent service), while the maximum temperature in the nozzle is reached at the exit of the nozzle and is $1680 \mathrm{~K}$, below the maximum for the silicon carbide (which is $\sim 1900 \mathrm{~K}$ in an oxidizing atmosphere). In this condition, the maximum positive value of the first principal stress in the nozzle occurs in the outer part of the flange and is $\sim 30 \mathrm{kpsi}(206 \mathrm{MPa})$. The tensile strength of silicon carbide is represented in the published data as a cumulative probability of failure. ${ }^{14}$ Although there is scatter in the data and a trend of increasing strength with 
temperature, the probability of failure typically rises above 0 at $\sim 22 \mathrm{kpsi}(150 \mathrm{MPa})$ and approaches 1 at $\sim 44 \mathrm{kpsi}$ $(300 \mathrm{MPa})$. Thus there is a chance of nozzle failure under the calculated conditions. High thermal stresses are associated with high temperature gradients, particularly in the radial direction. Note that with flow in the coflow nozzle the nozzle temperature is reduced to $\sim 1200 \mathrm{~K}-1400 \mathrm{~K}$, reducing temperature gradients and thermal stresses to acceptable levels. Increasing the contact thermal resistance of the gasket increases the temperature of the nozzle in the flange area, but also reduces temperature gradients and thermal stresses.

Time-dependent calculations were performed in which the temperature of the assembly was initially $300 \mathrm{~K}$. These showed that, while the component temperatures increase monotonically towards the steady state, the maximum stress peaked at as much as two times the steady state value at around $10 \mathrm{~s}$, before falling to steady state. This is because thermal stresses depend upon temperature differences within the nozzle, especially in the radial direction, and upon the thermal expansion coefficient. The nozzle flow surface temperature rises more rapidly than temperatures some distance from the surface, causing an overshoot in temperature differences. The problem is worsened by the increase in thermal expansion coefficient with temperature.

To avoid failure in the nozzle, the burner, in practice is always operated with coflow. No problems with the nozzle have been encountered over a wide range of conditions. If operation without coflow were to be attempted at the high-heat-flux conditions then the graphite gaskets would have to be replaced with insulating gaskets from a material such as mica. For operation without coflow it would be desirable to water cool the annulus.

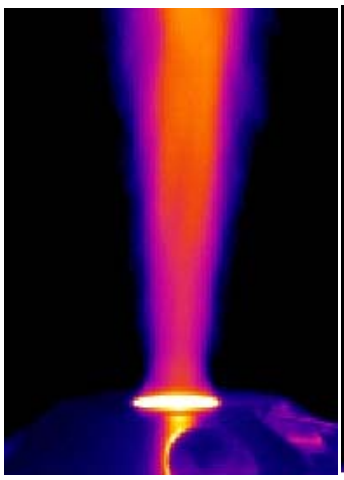

(a)

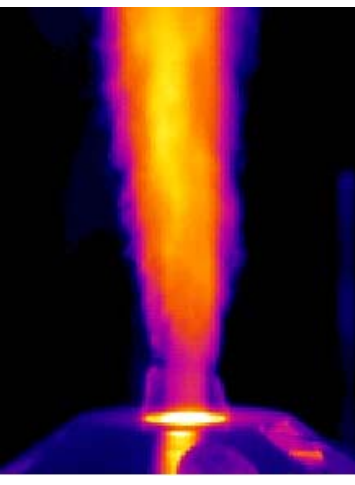

(b)

Figure 8. Comparison of attached flames as observed in the infrared: (a) base attached flame ( $M=1, T=1700 \mathrm{~K}$, vitiated $\mathrm{H}_{2}$ with air coflow) and (b) external attached flame ( $M=1$, $M_{\text {enthalpy }}=7, \mathrm{H}_{2}$ vitiated air with $\mathrm{H}_{2}$ coflow).

\begin{tabular}{|c|c|c|c|c|}
\cline { 2 - 5 } \multicolumn{1}{c|}{} & $M=1$ & $M=1.6$ & \multicolumn{2}{c|}{$M=2$} \\
\hline$M_{\text {enthalpy }}$ & $\mathrm{ER}=1$ & $\mathrm{ER}=1$ & $\mathrm{ER}=0.5$ & $\mathrm{ER}=1$ \\
\hline 5 & 0 & $\mathrm{EAF}$ & & \\
5.5 & $\mathrm{EAF}$ & $\mathrm{EAF}$ & $\mathrm{N}$ & $\mathrm{N}$ \\
6 & $\mathrm{EAF}$ & $\mathrm{EAF}$ & $\mathrm{N}$ & $\underline{\mathrm{M}-\mathrm{DF}}$ \\
6.5 & $\mathrm{EAF}$ & $\mathrm{EAF}$ & $\mathrm{DF}$ & $\mathrm{DF}$ \\
7 & $\mathrm{EAF}$ & $\mathrm{EAF}$ & $\underline{\mathrm{DF}}$ & $\underline{\mathrm{DF}}$ \\
\hline
\end{tabular}

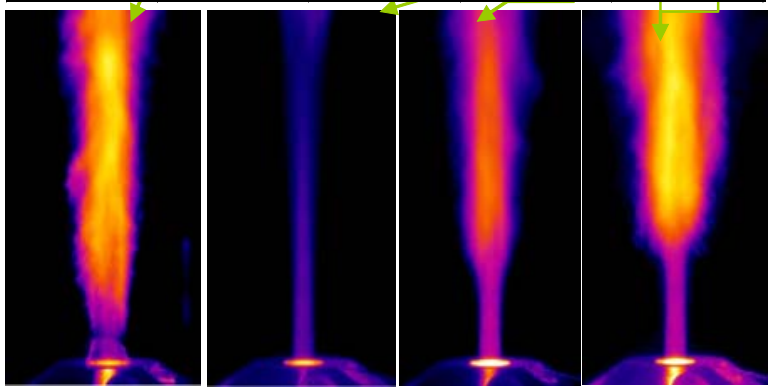

Figure 9. Matrix of burner operating conditions with several nozzles $(M=1,1.6$ and 2$) . H_{2}$-vitiated air center jet with $\mathrm{H}_{2}$ coflow. Infrared (false color) images. Red box refers to case with CARS data.

\section{Flow Visualization of Test Matrix}

The flowfield at the exit of the burner was visualized by employing either an infrared (IR) camera or a visible light color consumer-grade digital camera (and sometimes both). The IR camera was a FLIR Systems Thermacam SC3000 imaging in the $8-9$ micron (long wave) region; the effective shuttering time of this camera is significantly less than $0.3 \mathrm{~ms}$, allowing some of the unsteady structure to be resolved. The visible light camera exposure time was $\sim 1 \mathrm{sec}$, long in relation to the unsteady structure. Intermittent operational problems with the IR camera required that the visible camera be used as a second choice on some runs.

Figures 8-12 contain tables and flow images showing the various types of flames observed in the test matrix. The tables contain information pertaining to the following states of the flame: no flame (NF), detached flame (DF), flame attached at the base (BAF) or at the external coflow boundary (EAF), and whether the flame holding is marginal, i.e., at the point of extinction (M). Figure 8 contains IR images that illustrate the two types of attached flame. The BAF in Fig. 8(a) is a flame that extends to the annular base region between the central and coflow nozzle exits, where the flow is recirculating. The existence of a flame here indicates that the ratio of fuel to air that enters this region through mixing is within the range of flammability. This type of flame seems only to be observed 
with vitiated hydrogen in the center jet. The EAF appears to be a diffusion flame that reaches to the burner surface at the boundary between the coflow and the ambient air. This flame is possible only in cases where the coflow is a fuel, occurring because of the low subsonic speed of the coflow. Notice some asymmetry in the EAF flame of Fig 8(a): this is believed to be due to the burner being assembled with the silicon carbide nozzle slightly off center, causing the width of the coflow nozzle exit to vary slightly around the circumference.

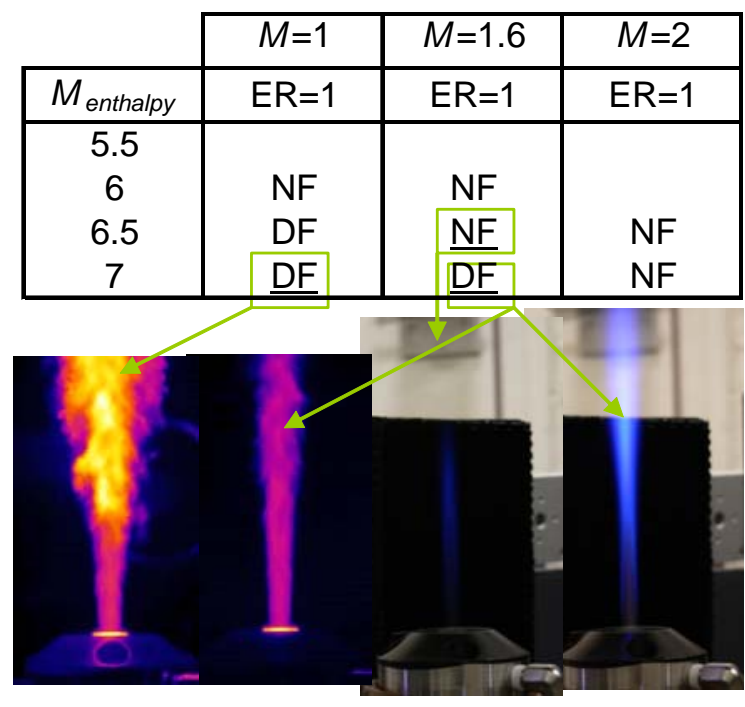

Figure 10. Matrix of burner operating conditions with $\mathrm{H}_{2}$ vitiated air center jet and $\mathrm{C}_{2} \mathrm{H}_{4}$ coflow. Infrared (false color) and visible light images.

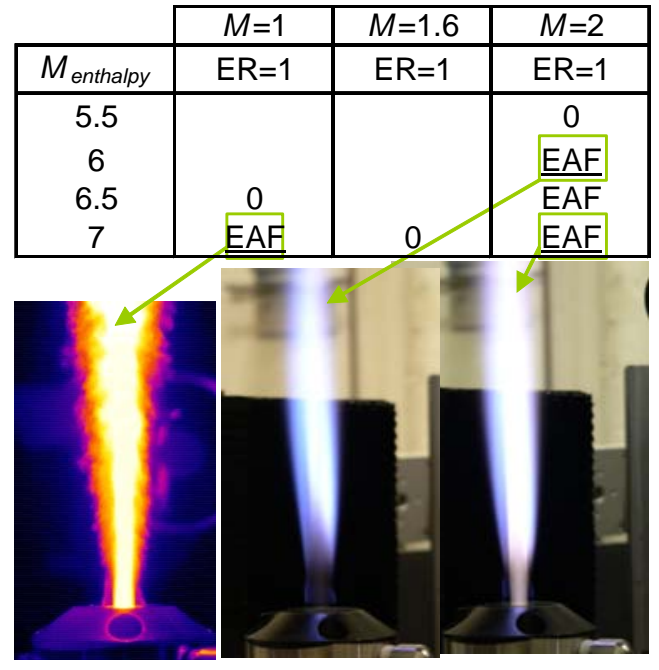

Figure 11. Matrix of burner operating conditions with $\mathrm{C}_{2} \mathrm{H}_{4}$ vitiated air center jet and $\mathrm{H}_{2}$ coflow. Infrared (false color) and visible light images.

Figure 9 shows IR images for cases with $\mathrm{H}_{2}$-vitiated air in the center jet and $\mathrm{H}_{2}$ in the coflow. The sensible enthalpy of the center jet is varied from that of Mach 5 flight to that of Mach 7; the exit Mach number of the center jet is $1.0,1.6$, and 2.0 ; and the equivalence ratio is 0.5 and 1 . For $M=1$ and 1.6 an exterior attached flame is observed in all cases, whereas for $M=2$ there is either no flame or the flame is detached (stands off from the nozzle exit). Where the flame is detached it spreads rapidly, perhaps being coupled with shock waves. The trend with increasing center jet enthalpy for a detached flame is for the flame to move towards the nozzle exit.

Figure 10 shows both IR and visible images for cases with $\mathrm{H}_{2}$-vitiated air in the center jet and $\mathrm{C}_{2} \mathrm{H}_{4}$ in the coflow. The IR images indicate a detached flame for cases at center jet Mach numbers of 1 and 1.6, and at the highest enthalpy. The visible images show that the detached flame is associated with a deep blue emission, perhaps $\mathrm{CH}$ or $\mathrm{C}_{2}$ emission. In other cases there is no combustion in the jet, although some emission is observed, indicating perhaps some dissociation of the $\mathrm{C}_{2} \mathrm{H}_{4}$. Comparison of the table entries with Figure 9 shows that $\mathrm{C}_{2} \mathrm{H}_{4}$ has poorer flameholding than $\mathrm{H}_{2}$, as is expected based on measurements of extinction. ${ }^{20}$

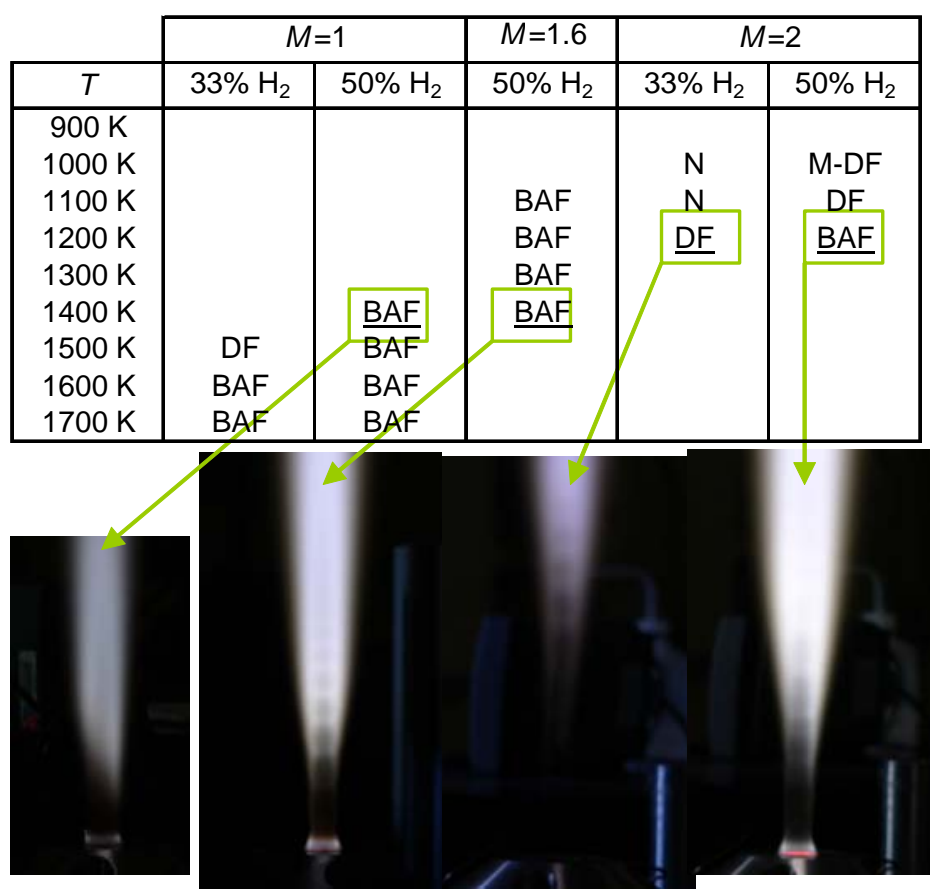

Figure 12. Matrix of burner operating conditions with vitiated $\mathrm{H}_{2}$ center jet and sonic air coflow. Visible light images. 
Figure 11 shows both IR and visible images for cases with $\mathrm{C}_{2} \mathrm{H}_{4}$-vitiated air in the center jet and $\mathrm{H}_{2}$ in the coflow. The IR images indicate an exterior attached flame for all cases that lighted. The limiting factor is whether or not combustion takes place in the burner. The 0 's in the matrix indicated that it would not take place. Where it was possible to light the burner at all it was lit at the Mach 7 flight enthalpy condition; for the $M=2$ nozzle case, once lit, it was found to be possible to reduce the enthalpy and the burner remain lit. Emissions levels in the center jet are higher than for the $\mathrm{H}_{2}$-vitiated cases. In the IR this may reflect emission from the $\mathrm{CO}_{2}$. In the visible this may reflect the presence of soot or soot precursers. Comparison with Figure 9 shows that $\mathrm{H}_{2}$ has better flame holding with the $\mathrm{C}_{2} \mathrm{H}_{4}$-vitiated air than the cases with $\mathrm{H}_{2}$ vitiation. This may be due to higher concentration of radical species or soot precursors in the center jet. If true, the results with this small burner may not be representative of the effect of vitiation in large scale hypersonic propulsion test facilities, where, presumably, the facility burns the fuel to a nearly equilibrium state.

Figure 12 shows visible light images for cases with vitiated $\mathrm{H}_{2}$ in the center jet, either $33 \%$ or $50 \%$ by volume of the jet flow being $\mathrm{H}_{2}$. The flame is made visible by a pale blue emission from the $\mathrm{OH}$ radical. In some cases, no flame is observed, in others detached flames or flames attached at the base. The trend with increasing $T$ is from no flame, to a detached flame, and then to a base-attached flame. There seems to be no consistent effect of $M$ on flame holding, although at higher $M$ the flame is larger downstream due to the greater flow rates of both vitiated air and coflow $\mathrm{H}_{2}$. One feature of these flames was a high level of noise. This noise increased as the enthalpy was reduced and the flame became more unstable. Also, the quality of the noise changed, from white noise for an attached flame, to a low pitched "rumbling" sound as the flame became detached, and finally to a "crackling" noise before the flame went out. This severe noise is neither conducive to operator nor to optical system presence in the laboratory.

\section{Optical Diagnostics Measurements}

\section{A. The Dual-Pump CARS-IRS Method}

The dual-pump CARS system ${ }^{21}$ uses a seeded Nd:YAG laser at $532 \mathrm{~nm}$ (green) and a narrow-band dye laser at $553 \mathrm{~nm}$ (yellow) as pump beams and a spectrally broad dye laser centered at $607 \mathrm{~nm}$ (red) as the Stokes beam. Some of the green laser is used for pumping the yellow pump and red Stokes dye lasers. The frequency difference between the green and red beams corresponds to the vibrational Raman shift of $\mathrm{N}_{2}$. The wavelength of the yellow pump beam is such the frequency difference between the yellow and red beams equals the vibrational Raman shift of $\mathrm{O}_{2}$. Therefore the CARS system probes $\mathrm{N}_{2}, \mathrm{O}_{2}$, and also $\mathrm{H}_{2}$ because pure rotational $\mathrm{H}_{2}$ transitions are present in both spectral regions. The laser beams are combined at the focusing point of a spherical lens in a folded BOXCARS geometry, generating a measurement volume of about $1.5 \mathrm{~mm} \times 0.2 \mathrm{~mm} \times 0.2 \mathrm{~mm}$. The coherent CARS signal beam generated at $491 \mathrm{~nm}$ (blue) is collected and collimated by another spherical lens, focused on the input slit of a onemeter spectrometer, and the spectra are recorded on a cooled CCD camera. Post-processing software fit spectra with a theoretical model. The shape of these spectra provides information on the temperature while the relative intensities of these spectra provide a measure of the relative mole fractions.

The interferometric Rayleigh scattering system ${ }^{9,10,21}$ uses as the light source the same green laser used by the CARS system. To increase the Rayleigh signal and to avoid laser-induced gas breakdown, an energy storage delay line of about $18 \mathrm{nsec}$ (pulse stretcher) is used in the green beam optical path. The receiving optics collect Rayleigh scattered light from two directions, the scattered light from the yellow and the red CARS beams is removed, and the remaining green light is passed through a solid etalon. To provide a reference, green light directly from the laser (not Rayleigh scattered) is also injected into the etalon. An electron multiplication gain CCD camera records the interference fringe pattern, which is formed at the output of the etalon. Interferogram processing software extract Rayleigh spectra and fitting algorithms solve for Doppler shift and implicitly for velocity.

\section{B. Preliminary Results}

Figure 13 shows some preliminary dual-pump CARS measurements acquired along a diameter at $2 \mathrm{~mm}$ above the nozzle exit, with the $M=1.6$ nozzle, $\mathrm{H}_{2}$-vitiated air at $M_{\text {enthalpy }}=6$ and $\mathrm{H}_{2}$ coflow. A visible light image of this flame is inset in Fig. 13(a) - see also the matrix in Fig. 9. The nozzle exit conditions calculated with 1D flow assumptions, and assuming 20\% heat loss (see Section IIIB) are: $V=1064 \mathrm{~m} / \mathrm{s}, T=1094 \mathrm{~K}$, and mole fractions of $\mathrm{N}_{2}$ and $\mathrm{O}_{2}$ of 0.589 and 0.193 respectively. For this data set, the CARS measurement volume was scanned at a constant rate across the jet diameter in a direction parallel to the laser beams while acquiring 1000 points at $20 \mathrm{~Hz}$. Single shot (instantaneous measurements) are plotted. In the nozzle base and coflow jet regions, in the range $5 \mathrm{~mm}$ $<|\mathrm{x}|<9 \mathrm{~mm}$, there was insufficient $\mathrm{N}_{2}$ to obtain meaningful fits of the CARS spectral to obtain temperature and composition. No data is shown in these regions. This absence of $\mathrm{N}_{2}$ (and also $\mathrm{O}_{2}$ ) in the base region explains the 
lack of any flame here. (As previously noted, this case had an external attached flame.) Elsewhere, $94 \%$ of the data were successfully fit. The data are seen to scatter around the trend lines. This scatter is due in part to instrument random error, and in part to turbulent fluctuations. The temperature varies symmetrically, from about $1400 \mathrm{~K}$ at the axis down to less than $800 \mathrm{~K}$ at the edge $(x= \pm 5 \mathrm{~mm})$. This variation is attributed to heat transfer to the burner and nozzle walls. The 1D static temperature based on an assumed heat loss of $20 \%$ is $1094 \mathrm{~K}$; if the assumed heat loss is reduced to zero, the $1 \mathrm{D}$ static temperature is $1300 \mathrm{~K}$, still $100 \mathrm{~K}$ below the centerline observation. On the other hand, the mole fractions of $\mathrm{O}_{2}$ and $\mathrm{N}_{2}$ are fairly flat in the center $(x= \pm 4 \mathrm{~mm})$ region of the jet, and compare well with the $1 \mathrm{D}$ values. At the outer edge of the coflow jet $(\mathrm{x}=9 \mathrm{~mm})$ there are some high temperatures, which may be the external attached flame. However, the data here should be treated with suspicion since the spatial resolution is insufficient to resolve this part of the flow.
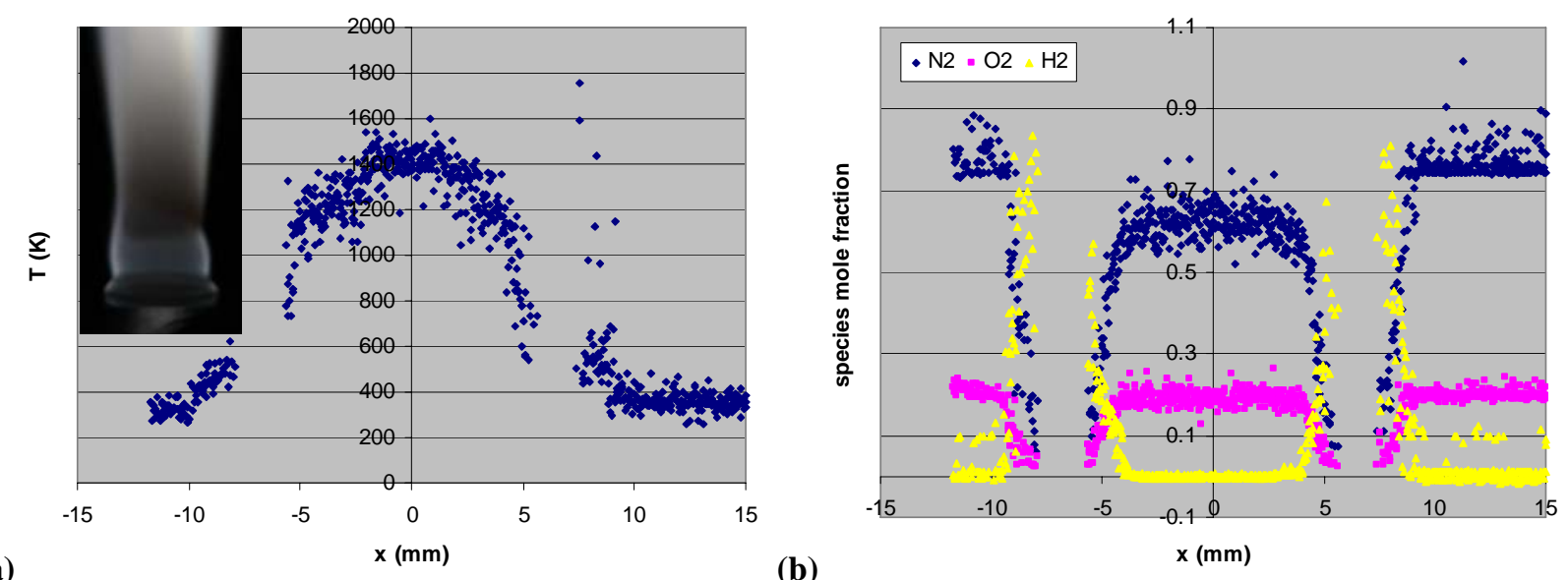

\section{(b)}

Figure 13 Dual-pump CARS measurements along a diameter at $2 \mathrm{~mm}$ above the nozzle exit, with $M=1.6 \mathrm{H}_{2}$ vitiated air at $M_{\text {enthalpy }}=6$ and $\mathrm{H}_{2}$ coflow. (a) Temperature (inset is visible light image of flame), (b) species mole fractions.

Interferometric Rayleigh scattering data were not acquired at $2 \mathrm{~mm}$ above the flow due to interference of scattered light from the nozzle exit. Data were acquired (simultaneously with CARS) at other locations. This data is still being analyzed, although some is presented in the companion paper by Tedder et al. ${ }^{21}$. The intent herein is to present data that can be compared with calculations for the purpose of verifying our techniques.

\section{Summary and Conclusions}

This paper describes progress towards generating an experimental data set that can be used by CFD modelers to develop models for turbulent supersonic combusting flows. A laboratory supersonic scale burner is described which duplicates, in essential features, the flow of a larger facility in which the final experimental data is to be acquired. The flowfield consist of an axisymmetric free jet of hot reaction product and an unheated annular coflow jet. By selection of the composition of burner reactants and coflow, a supersonic free jet with combustion can be created. This burner has been designed to verify the choice of experimental test conditions of the final experiments, and to verify the optical diagnostic instruments that will be employed. The calculated range of available flow conditions of the burner is described, along with some detailed design calculations. The burner is operated over a wide matrix of available conditions, and the supersonic combusting jets are visualized in the visible and infrared wavelengths to assess flame holding. The final experiment flow field will be mapped using the dual pump CARS-IRS technique, which can provide simultaneous temperature, composition, and velocity. From series of such measurements, many of the turbulence statistics of interest to modelers can be found. The fluid dynamical length scales of the laboratory facility are not small in relation to the CARS system measurement volume; hence the scale of the final experiment will be more than six times larger. However, the small burner may provide useful data using other techniques with better spatial resolution. In this paper we have discussed the CARS-IRS technique and presented a sample of some preliminary experimental data acquired in the laboratory burner to verify it.

The ability to create a supersonic combusting jet suitable for study with optical techniques has been demonstrated. These cases have fully compressible mixing layers. Cases with flame holding and with flame standoff, as well as with both $\mathrm{H}_{2}$ and $\mathrm{C}_{2} \mathrm{H}_{6}$ fuels are available. The dual-pump CARS-IRS technique has been demonstrated, and some shortcomings identified. 


\section{Acknowledgments}

This work was supported by Mr. George Rumford, program manager of the Defense Test Resource Management Center's (DTRMC) Test and Evaluation/Science and Technology (T\&E/S\&T) program, under the Hypersonic Test focus area, and by the NASA Langley Research Center from NASA's Fundamental Aeronautics Hypersonics Program. The authors would like to thank L.G. Wilson for technical support in performing these experiments; M. Weikl, Dr. F. Beyrau, and Dr. T. Seeger, Universität Erlangen-Nürnberg, Erlangen, Germany for assistance in setting up the CARS system and acquiring the CARS data; and Dr J. P. Drummond for leadership of the combined CFD and experimental effort at NASA Langley. The first author acknowledges additional financial support under NASA grant NNL06AA16A, technical monitor Dr. A.H. Auslender.

\section{References}

${ }^{1}$ Baurle, R.A., "Modeling of High Speed Reacting Flows: Established Practices and Future Challenges," AIAA 2004-267, 42nd Aerospace Sciences Meeting and Exhibit, Reno, NV, 5-8 Jan, 2004.

${ }^{2}$ Goyne, C.P., McDaniel, J.C., Krauss, R.H., Day, S.W., "Velocity measurement in a dual-mode supersonic combustor using particle image velocimetry," AIAA Paper 2001-1761, AIAA/NAL-NASDA-ISAS International Space Planes and Hypersonic Systems and Technologies Conference, 10th, Kyoto, Japan, Apr. 24-27, 2001. ${ }^{3}$ Cutler, A.D., Danehy, P.M., Springer, R.R., O’Byrne, S., Capriotti, D.P., DeLoach, R., "Coherent Anti-Stokes Raman Spectroscopic Thermometry in a Supersonic Combustor," AIAA J., Vol. 41, No. 12, Dec. 2003.

${ }^{4}$ Lucht, R.P., "Three-laser coherent anti-Stokes Raman scattering measurements of two species," Optics Letters, Vol. 12, No. 2, February 1987, pp. 78-80.

${ }^{5}$ Hancock, R.D., Schauer, F.R., Lucht, R.P. and Farrow, R.L., "Dual-pump coherent anti-Stokes Raman scattering measurements of nitrogen and oxygen in a laminar jet diffusion flame," Applied Optics, Vol. 36, No. 15, 1997.

${ }^{6}$ O’Byrne, S., Danehy, P.M., Cutler, A.D., "Dual-Pump CARS Thermometry and Species Concentration Measurements in a Supersonic Combustor, AIAA Paper 2004-0710, 42nd Aerospace Sciences Meeting, Reno, NV, Jan. 5-8, 2004.

${ }^{7}$ Tedder, S. A., O’Byrne, S., Danehy, P. M., Cutler, A. D., "CARS Temperature and Species Concentration Measurements in a Supersonic Combustor with Normal Injection," AIAA Paper 2005-0616, 43rd AIAA Aerospace Sciences Meeting, Reno, NV, Jan 10-13, 2005.

${ }^{8}$ Bresson, A., Bouchardy, P., Magre, P., Grisch, F., "OH/acetone PLIF and CARS thermometry in a supersonic reactive layer," AIAA Paper 2001-1759, AIAA/NAL-NASDA-ISAS International Space Planes and Hypersonic Systems and Technologies Conference, 10th, Kyoto, Japan, Apr. 24-27, 2001.

9 Bivolaru, D., Danehy, P.M., Lee, J.W., Gaffney, R.L., Cutler, A.D., "Single-pulse, Multi-point Multi-component Interferometric Rayleigh Scattering Velocimeter," AIAA-2006-836, 44th AIAA Aerospace Sciences Meeting, Reno, NV, 9-12 Jan., 2006.

${ }^{10}$ Bivolaru, D., Grinstead, K. D., Tedder S., Lee, J. W., Danehy, P.M., Cutler A. D., "Simultaneous Temperature, Concentration, and Velocity Measurements for Combustion Using CARS and Rayleigh Scattering," AIAA AMTGT Technology Conference, San Francisco, June, 2007.

${ }^{11}$ Gaffney, R.L., Jr., Cutler, A.D., "CFD Modeling Needs and What Makes a Good Supersonic Combustion Experiment," JANNAF Meeting, June 2005.

${ }^{12}$ Drummond, J.P., Danehy, P.M., Bivolaru, D., Gaffney, R.L., Parker, P., Chelliah, H.K., Cutler, A.D., Givi, P., Hassan, H.A., "Predicting the Effects of Test Media in Ground-Based Propulsion Testing," 2006 Annual ITEA Technology Review, Cambridge, MA, August 7-10, 2006

${ }^{13}$ Zucrow, M. J., Hoffman, J. D., Gas Dynamics - Vol II - Multidimensional Flow, pp. 87-103, Krieger, 1985.

${ }^{14} \mathrm{SiC}$ Ceramic Materials for Design of High-Performance Applications, Form A-12,047, St-Gobain Industrial Ceramics, 1997, available http://www.carbo.com/hexoloy data-sheets .

${ }_{15}$ Auslender, A.H., "An Application of Distortion Analysis to Scramjet Combustor Performance Assessment," Final Report, 1996 JANNAF Propulsion and Joint Subcommittee Meeting Scramjet Performance Workshop, Dec. 12, 1996.

${ }^{16}$ Papamoschou, D., Roshko, A., "The compressible turbulent shear layer: an experimental study,” J. Fluid Mech., vol. 197, pp. 453-477, 1988.

${ }^{17}$ White, J.A., Morrison, J. H., “A Pseudo-Temporal Multi-Grid Relaxation Scheme for Solving the Parabolized Navier-Stokes Equations,” AIAA Paper 99-3360, June 1999. 
${ }^{18}$ Edwards, J.R., "A Low Diffusion Flux-Splitting Scheme for Navier-Stokes Calculations," Computers \& Fluids, Vol. 26, No. 6, pp. 635-659, 1997

${ }^{19}$ Wilcox, D. C., Turbulence Modeling for CFD, $2^{\text {nd }}$ Edition, DCW Industries, 1998.

${ }^{20}$ Pellett, G.L., Convery, J.L., Wilson, L.G., "Opposed Jet Burner Approach for Characterizing Flameholding Potentials of Hydrocarbon Scramjet Fuels," AIAA 2006-5233, 42nd AIAA/ASME/SAE/ASEE Joint Propulsion Conference \& Exhibit, Sacramento, CA, 9-12 July 2005

${ }^{21}$ Tedder, S., Bivolaru, D., Danehy, P.M., Weikl, M., Beyrau, F., Seeger, T., Cutler, A.D., "Characterization of a Combined CARS and Interferometric Rayleigh Scattering System and Demonstration in a Mach 1.6 CombustionHeated Jet," AIAA-2007-871, 45 ${ }^{\text {th }}$ AIAA Aerospace Sciences Meeting, Reno, NV, 8-11 Jan., 2007. 